\title{
İlk Defa Sentezlenen Eperezolid Benzeri Bileşiklerin Anti-Üreaz ve Anti-Elastaz Enzim Aktivitelerinin İncelenmesi
}

\author{
Bahar BİLGIN SÖKMEN ${ }^{1 *}$, Dilem ŞEN ${ }^{1}$, Aylin KURT ${ }^{1}$, Hakan BEKTAŞ ${ }^{1}$, Hatice PUSTİ ${ }^{1}$ \\ ${ }^{1}$ Giresun Üniversitesi, Fen Edebiyat Fakültesi, Kimya Bölümü, 28049, Giresun, Türkiye
}

Geliş Tarihi: 19.11 .2018

"Sorumlu Yazar: bahar.sokmen@giresun.edu.tr

Kabul Tarihi: 08.05.2019

$\ddot{\mathbf{O z}}$

İlk defa sentezlenmiş olan oksazolidinon türevi eperezolid benzeri bileşiklerin antiüreaz ve anti-elastaz aktiviteleri incelendi. En yüksek ve en düşük antiüreaz aktivite sırasıyla $8\left(\mathrm{IC}_{50}=1.91 \times 10^{-3} \pm 2.97 \times 10^{-4} \mu \mathrm{M}\right)$ ve $\mathbf{1 0}$ bileşiklerinde $\left(\mathrm{IC}_{50}=6,03 \times 10^{-3} \pm 1,98 \times 10^{-4} \mu \mathrm{M}\right)$ gözlendi. En yüksek ve en düşük anti-elastaz aktivite ise sirasılyla $8\left(\mathrm{IC}_{50}=2,2 \times 10^{-2} \pm\right.$ $\left.2,6 \times 10^{-3} \mu \mathrm{M}\right)$ ve 1 bileşiklerinde $\left(\mathrm{IC}_{50}=4,1 \times 10^{-2} \pm 1,3 \times 10^{-3} \mu \mathrm{M}\right)$ gözlendi.

Anahtar Kelimeler: Eperezolid, Anti-üreaz, Anti-elastaz, İnhibitör.

\section{The Investigation of Anti-Urease and Anti-Elastase Activities of Firstly Synthesized Eperezolide-like Derivatives}

\begin{abstract}
Antiurease and anti-elastase activities of the oxazolidinone derived eperezolid-like compounds which were synthesized for the first time were examined. The highest and lowest antiurease activity were observed in the compounds $\mathbf{8}$ (IC $_{50}=$ $\left.1.91 \times 10^{-3} \pm 2.97 \times 10^{-4} \mu \mathrm{M}\right)$ and $10\left(\mathrm{IC}_{50}=6,03 \times 10^{-3} \pm 1,98 \times 10^{-4} \mu \mathrm{M}\right)$, respectively. The highest and lowest anti-elastase activities were observed in compounds $8\left(\mathrm{IC}_{50}=2,2 \times 10^{-2} \pm 2,6 \times 10^{-3} \mu \mathrm{M}\right)$ and $\mathbf{1}\left(\mathrm{IC}_{50}=4,1 \times 10^{-2} \pm 1,3 \times 10^{-3} \mu \mathrm{M}\right)$, respectively.
\end{abstract}

Keywords: Eperezolide, Anti-urease, Anti-elastase, Inhibitor. 


\section{Giriş}

Eperezolit, 2000'li yılların başında linezolid ile birlikte pfizer tarafından geliştirilen Linezolidden sonra piyasaya çıkan ikinci oksazolidinon türevi antibiyotiktir. Organik sentez yoluyla elde edilen bir antimikrobiyaldir. Bakteriyel protein sentezini inhibe ederek etki göstermektedir. Eperezolit, benzimidazollerin yeni bir antibakteriyal bileşik sınıfı olan oksazolidinonlar içerisinde yer alan, organik olarak sentezlenebilen antimikrobiyal bir ilaç olup, bakteriyostatik etkilerini, bakteri protein sentezini inhibe ederek gösterirler. Aerobik gram (+) bakterilerde ve bazı gram (-) bakterilerde etkindirler. Toplum kaynaklı pnömonilerin, deri ve yumuşak doku enfeksiyonların tedavisinde kullanılmaları önerilmektedir (Leblebicioğlu ve ark., 2003).

Üreaz (Üreamidohidrolaz; EC 3.5.1.5), nikel bağlı hidrolaz sınıfı bir metaloenzimdir. Üreaz enzimi, üreyi amonyak ve karbondioksite hidroliz eder. Başlıca; bitkiler, bakteriler ve funguslar tarafindan sentezlenmektedir (Mobley ve Hausinger, 1989). Helicobacter pylori bakterisinin midede meydana getirdiği enfeksiyonları engellemek amacıyla üreaz inhibitörleri olarak da bilinen proton pompası inhibitörleri (PPİ) kullanılmaktadır. Günümüzde kullanılan PPİ’leri lansoprazol, omeprazol, ranitidin ve floramid gibi antiülser ilaçlarıdır (Özer ve ark., 2004).

Elastaz (E.C.3.4.21.36), kollajen ve elastini parçalayan klasik bir metalloproteaz enzimidir. Elastin ise cilt, akciğer dokusu, deri ve arterler de dahil olmak üzere bağ dokularında bulunan, doku yapısının korunmasına yardımcı olan önemli bir proteindir (Delden ve Iglewski, 1998). Elastaz üretiminin, özellikle akciğer dokusuna yerleşme ve yayılmasında önemli bir virülans faktörü olduğu bildirilmektedir (Demir ve ark., 2008). Elastiyolitik aktivite, akut enfeksiyon oluşumunun başlangıç evresinde elastin içeren akciğer dokusunun yapısının bozulmasına ve doku içi kanamalara neden olmaktadır (Delden ve Iglewski, 1998). Bunun yanı sıra, ultraviyole (UV) ışınlarına aşırı maruz kalmak, cilt elastikiyetini azaltarak, kırışıklıklara ve sarkmalara yol açabilmektedir (Braverman ve Fonferko, 1982). Literatürde spesifik elastaz inhibitörlerinin (Kateşin, purpurin, vb.) UV 1şınları yada başka sebeplerle oksidatif hasara uğramış cilt üzerine topikal olarak uygulamasıyla yararlı etkiler oluşturabileceği bildirilmektedir (Liyanaarachchi ve ark., 2018).

$\mathrm{Bu}$ çalışmada, yeni sentezlenmiş eperezolid benzeri bileşiklerin üreaz ve elastaz enzimlerine inhibisyon etkilerinin incelenmesi amaçlanmıştır. 


\section{Materyal ve Metot}

\subsection{Kullanılan Cihazlar}

Absorbans ölçümlerinde Shimadzu UV Mini-1240 model UV-VIS Spektrofotometre kullanıld1. pH metre Butech, hassas terazi Sartorius, manyetik karıştırıcı Chiltern Hotplate HS 31, vorteks Velp Scientifica, çalkalamalı su banyosu Memmert, sonik su banyosu Selectra marka kullanıldı.

\subsection{Anti-üreaz ve Anti-elastaz Aktivite Tayinleri}

Giresun Üniversitesi Fen Edebiyat Fakültesi, Kimya Bölümü Öğretim Üyesi Doç. Dr. Hakan BEKTAŞ tarafından Organik Kimya Laboratuvarında oksazolidinon türevi eperezolid benzeri bileşikler ilk defa sentezlenmiştir. Bu çalışmada kullanılan bileşiklerin açık yapıları ve adlandırılmaları Tablo 1'de verilmektedir.

Tablo 1. Sentezlenen Eperezolid Benzeri Bileşikler

\begin{tabular}{|c|c|c|}
\hline $\begin{array}{l}\text { Bileşik } \\
\text { No }\end{array}$ & Açık Yapı & Sistematik Adı \\
\hline 1 & & 2-[4-(2-Florofenil)piperazin-1-il]asetohidrazid \\
\hline & & Etil[4-(2-florofenil)piperazin-1-il]asetat \\
\hline 3 & & $\begin{array}{l}\text { 2-\{[4-(2-florofenil)piperazin-1-il]asetil }\}-N \text {-fenilhidrazin } \\
\text { karbotiyoamid }\end{array}$ \\
\hline 4 & & $\begin{array}{l}\text { 5-\{[4-(2-florofenil)piperazin-1-il }] \text { metil }\}-4-\text { fenil- } 4 H-1,2,4- \\
\text { triazol-3-tiyol }\end{array}$ \\
\hline 5 & & $\begin{array}{l}\text { 1-(4-klorofenil)-2-[(5-\{[4-(2-florofenil)piperazin-1- } \\
\text { il]metil\}-4-fenil-4H-1,2,4-triazol-3-il)tiyo]etanon }\end{array}$ \\
\hline
\end{tabular}

Çalışmada ilk olarak, sentezlenen bileşiklerin uygun bir çözücü dimetil sülfoksit (DMSO) kullanılarak çözünmesi sağlandı ve aynı çözücü kullanılarak farklı konsantrasyonlara (1,0x10 $10^{-2}$ 


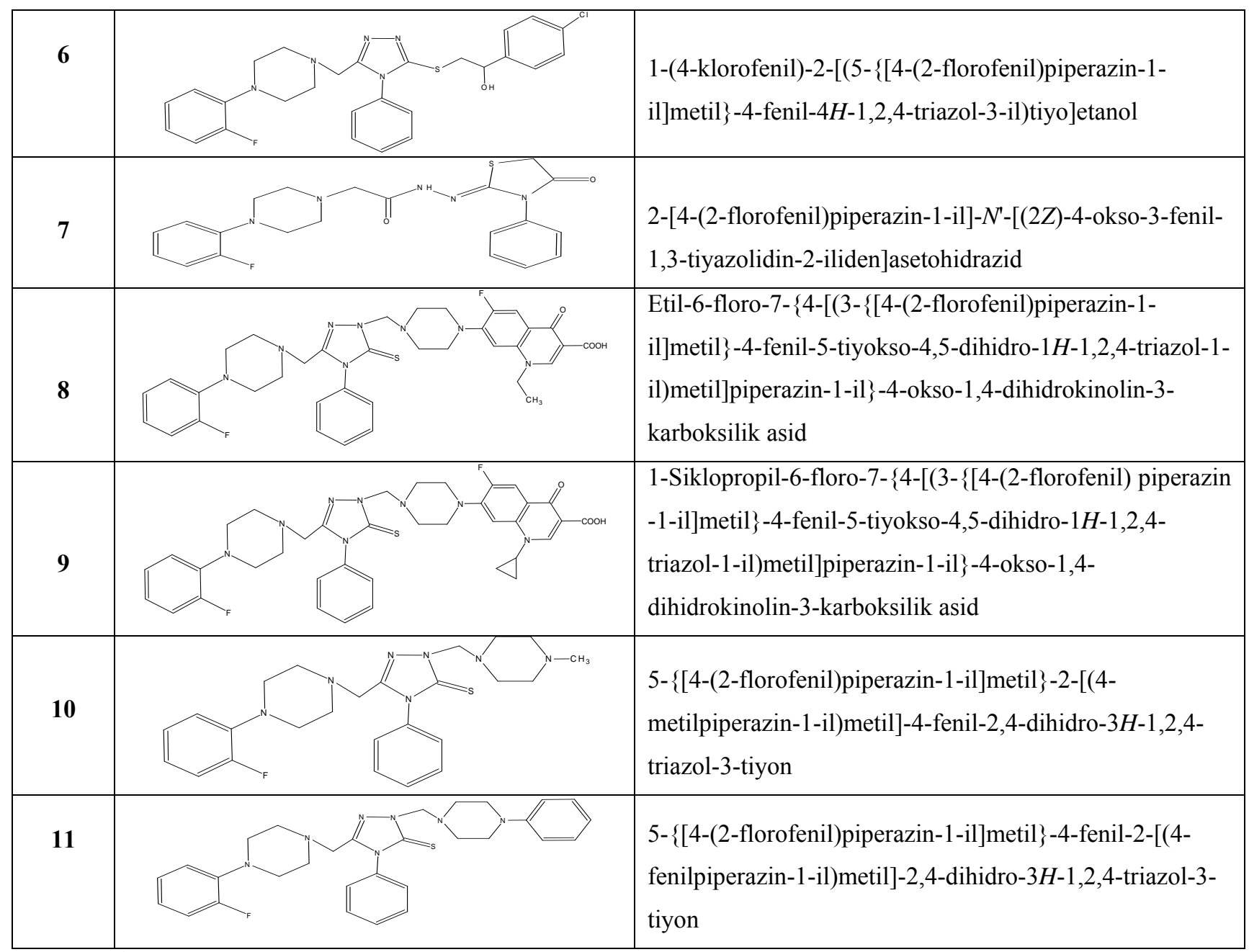

$\left.1,0 \times 10^{-6} \mu \mathrm{g} / \mathrm{mL}\right)$ seyreltildi. Anti-üreaz aktivite tayini Van Slike ve Archibald'ın spektrofotometrik yöntemlerine göre belirlendi (Van Slyke and Archibald, 1944). Üreaz enziminin (Jack bean) $100 \mathrm{mM}$ fosfat tamponunda (pH 6,8) hazırlanan çözeltisi; kontrol çözeltisi olarak $500 \mathrm{mM}$ üre içeren fosfat tamponu (pH 6,8) çözeltisi, fenol kırmızısı içeren üre fosfat tampon çözeltisi (pH 6,8) kullanılarak spektrofotometrede $570 \mathrm{~nm}$ 'de absorbans değerleri okundu.

Anti-elastaz aktivitesi, domuz pankreasından saflaştııılmış elastaz enzimi, pH'1 7,8 olan Tris hidroklorür tamponu ve N-Süksinil-Ala-Ala-Ala-p-nitroanilit (STANA) substratı kullanılarak 410 nm'de absorbansı ölçülerek tayin edildi (Ji-Young ve ark., 2010). Sentezlenen bileşiklerin DMSO kullanılarak farklı konsantrasyonlara $\left(1,0 \times 10^{-3}-1,0 \times 10^{-6} \mu \mathrm{g} / \mathrm{mL}\right)$ seyreltildi.

Deneyler 3 kez tekrarlandı ve ortalaması alındı. Her iki enzim inhibisyonu için bileşiklerin ve standart inhibitörlerinin \% inhibisyon değerleri aşağıdaki denkleme göre hesaplandı.

$$
\text { \% İnhibisyon= }=\left[\left(A_{\text {kontrol }}-A_{\text {örnek }}\right) / A_{\text {kontrol }}\right] \text { x } 100
$$

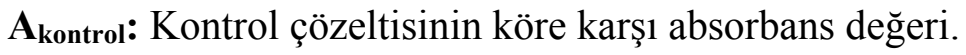

Ä̈rnek: İnhibitör çözeltisinin köre karşı absorbans değeri.

IC50 değerleri (Aktivitenin \%50'sini inhibe eden konsantrasyon değeri), her iki enzim inhibisyonu için absise konsantrasyon, ordinata \% enzim inhibisyon verilerinin uygulanması ile çizilen eğrinin lineer kesiminden elde edilen regresyon denkleminden hesaplandı. 


\section{Bulgular ve Tartışma}

Hem üreaz hem de elastaz enziminin inhibisyon değerlerinden hesaplanan $\mathrm{IC}_{50}$ değerleri Tablo 2'de verilmiştir. Eperezolid benzeri bileşikler arasında IC50 değerinin en düşük olması nedeniyle en yüksek anti-üreaz aktiviteyi $\mathbf{8}\left(\mathrm{IC}_{50}=1,91 \times 10^{-3} \pm 2,97 \times 10^{-4} \mu \mathrm{M}\right)$, en düşük ise $\mathbf{1 0}\left(\mathrm{IC}_{50}=6,03 \times 10^{-3} \pm\right.$

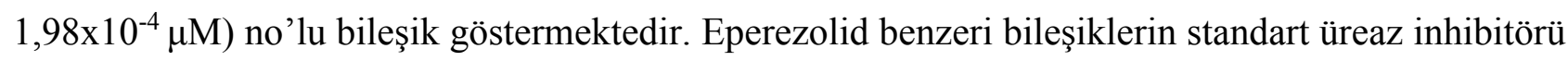
olan tiyoüreden çok daha etkili bir inhibisyon etkisine sahip oldukları görülmektedir. En yüksek antielastaz aktiviteyi $8\left(\mathrm{IC}_{50}=2,2 \times 10^{-2} \pm 2,6 \times 10^{-3} \mu \mathrm{M}\right)$, en düşük ise $\mathbf{1}\left(\mathrm{IC}_{50}=4,1 \times 10^{-2} \pm 1,3 \times 10^{-3} \mu \mathrm{M}\right)$ no'lu bileşik göstermektedir. Eperezolid benzeri bileşikler standart elastaz inhibitörü olan ursolik asite yakın değerlerde inhibisyon etkisi göstermiştir.

Tablo 2. Eperezolid Bileşiklerin Antiüreaz ve Anti-Elastaz Aktiviteleri

\begin{tabular}{|ccc|ccc|}
\hline $\begin{array}{l}\text { Bileşik } \\
\text { No }\end{array}$ & $\begin{array}{c}\text { Anti- Üreaz } \\
\mathbf{I C}_{\mathbf{5 0}}(\boldsymbol{\mu} \mathbf{M})^{*}\end{array}$ & $\begin{array}{c}\text { Anti-Elastaz } \\
\mathbf{I C}(\boldsymbol{\mu M})^{*}\end{array}$ & $\begin{array}{c}\text { Bileşik } \\
\text { No }\end{array}$ & $\begin{array}{c}\text { Anti- Üreaz } \\
\mathbf{I C}_{\mathbf{5 0}}(\boldsymbol{\mu M})^{*}\end{array}$ & $\begin{array}{c}\text { Anti-Elastaz } \\
\mathbf{I C}\end{array}$ \\
\hline $\mathbf{1}$ & $3,99 \times 10^{-3} \pm 55 \times 10^{-4}$ & $4,1 \times 10^{-2} \pm 1,3 \times 10^{-3}$ & $\mathbf{8}$ & $1,91 \times 10^{-3} \pm 2,97 \times 10^{-4}$ & $2,2 \times 10^{-2} \pm 2,6 \times 10^{-3}$ \\
$\mathbf{2}$ & $3,5 \times 10^{-3} \pm 2,40 \times 10^{-4}$ & $3,4 \times 10^{-2} \pm 3,4 \times 10^{-3}$ & $\mathbf{9}$ & $3,33 \times 10^{-3} \pm 1,41 \times 10^{-4}$ & $2,4 \times 10^{-2} \pm 2,3 \times 10^{-3}$ \\
$\mathbf{3}$ & $4,14 \times 10^{-3} \pm 5,80 \times 10^{-4}$ & $2,5 \times 10^{-2} \pm 1,9 \times 10^{-3}$ & $\mathbf{1 0}$ & $6,03 \times 10^{-3} \pm 1,98 \times 10^{-4}$ & $3,4 \times 10^{-2} \pm 1,5 \times 10^{-3}$ \\
$\mathbf{4}$ & $3,92 \times 10^{-3} \pm 6,15 \times 10^{-4}$ & $3,4 \times 10^{-2} \pm 2,8 \times 10^{-3}$ & $\mathbf{1 1}$ & $5,30 \times 10^{-3} \pm 1,09 \times 10^{-3}$ & $2,3 \times 10^{-2} \pm 1,2 \times 10^{-3}$ \\
$\mathbf{5}$ & $4,72 \times 10^{-3} \pm 3,61 \times 10^{-4}$ & $3,4 \times 10^{-2} \pm 2,4 \times 10^{-3}$ & Tiyoüre & $0,512 \pm 0,0259$ & - \\
$\mathbf{6}$ & $3,07 \times 10^{-3} \pm 2,55 \times 10^{-4}$ & $2,5 \times 10^{-2} \pm 2,4 \times 10^{-3}$ & Ursolik & - & $2,3 \times 10^{-2} \pm 1,4 \times 10^{-3}$ \\
$\mathbf{7}$ & $3,07 \times 10^{-3} \pm 2,12 \times 10^{-4}$ & $2,7 \times 10^{-2} \pm 9,0 \times 10^{-4}$ & asit & - & - \\
\hline
\end{tabular}

* Ortalama \pm Standart Sapma

Eş tarafından yapılan çalışmada; triazol türevlerinin anti-elastaz inhibitör aktiviteleri incelenmiş ve sentezlenen bileşiklerin orta düzeyde anti-elastaz aktivite gösterdiği bildirilmiştir [Eş, 2013). Menteşe ve ark., yeni sentezledikleri bir seri eperezolid benzeri bileşiğin antiüreaz aktivitesini incelemiş ve bileşiklerin iyi üreaz inhibitörü aktivitesine sahip olduğunu bildirmişlerdir (Mentese ve ark., 2017).

\section{Sonuçlar ve Öneriler}

Elde edilen sonuçlardan eperezolid benzeri bileşiklerin etkili üreaz ve elastaz inhibitör aktivitesine sahip olduğu sonucuna varılmıştır. Gelecekte üreaz ve elastaz enzimi ile ilgili hastalıkların tedavisi için terapötik yaklaşımların gelişimine in vitro çalışmalar da yapılarak katkı sağlayabileceği düşünülmektedir. 


\section{Kaynaklar}

Braverman, I.M., Fonferko, E. 1982. Studies in Cutaneous Aging:I. The Elastic Fiber Network. The Journal of Investigatve Dermatology, 78, 434-443.

Delden, C.V., Iglewski, B.H. (1998). Cell-to-cell Signalling and Pseudomonas aeruginosa Infections. Emerging Infectious Diseases, 4, 551-560.

Demir, M., Cevahir, N., Kaleli, İ., Yıldırım, U., Şahin, R., Çevik Tepeli, E. (2008). Alt Solunum Yolu Örnekleri Ve Solunum Dışı Örneklerden İzole Edilen Pseudomonas aeruginosa Suşlarında Siderofor, Total Matriks Proteaz Ve Elastaz Aktivitesinin Araştırılması. Mikrobiyoloji Bülteni, 42, 197-208.

Eş, S. (2013). İlk Defa Sentezlenen 1,2,4-Triazol Schiff Bazı Bileşiklerinin Antioksidan, Anti-Elastaz ve AntiTirozinaz Aktivitelerinin İncelenmesi, Yüksek Lisans Tezi, Giresun Üniversitesi, Fen Bilimleri Enstitüsü, Giresun.

Ji-Young, M., Eun-Young, Y., Gwanpil, S., Nam, H.L., Chang-Gu, H. (2010). Screening of Elastase and Inhibitory Activity from Jeju Island Plants. EurAsian Journal of BioSciences, 4, 41-53.

Leblebicioğlu, H., Usluer, G., Ulusoy, S. 2003. Güncel Bilgiler Işı̆̆ında Antibiyotikler. Bilimsel Tıp Yayınevi, Ankara.

Liyanaarachchi, G.D., Samarasekera, J.K.R.R., Mahanama, K.R.R., K.D.P, Hemalal. (2018). Tyrosinase, Elastase, Hyaluronidase, Inhibitory and Antioxidant Activity of Sri Lankan Medicinal Plants for Novel Cosmeceuticals. Industrial Crops and Products, 111, 597-605.

Mentese, E., Bektas, B., Bilgin Sokmen, B., Emirik, M., Çakır, D., Kahveci, B. (2017). Synthesis and Molecular Docking Study of Some 5,6-dichloro-2-cyclopropyl-1H-benzimidazole Derivatives Bearing Triazole, Oxadiazole, and Imine Functionalities as Potent Inhibitors of Urease. Bioorganic \& Medicinal Chemistry Letters, 27, 3014-3018.

Mobley, L., T, Hausinger, R. (1989). Microbial ureases: Significance, Regulation and Molecular Characterization. Microbiological Reviews, 53, 85-108.

Özer, B., Serin, E., Coşar, A., Kayaselçuk, F., Gür, G., Yılmaz, U. Boyacıŏlu, S. (2004). Helicobacter pylori Eradikasyon Tedavisinde Lansoprazol, Klaritromisin ve Amoksilin ile Ranitidin Bizmut Sitrat, Lansoprazol, Klaritromisin ve Amoksilin Rejimlerinin Etkinliğinin Karşılaştırılması. Akademik Gastroenteroloji Dergisi, 3, 125-128.

Van Slyke, D.D. Archibald, R.M. (1944). Manometric, Titrimetric and Colorimetric Methods for Measurements of Urease Activity. The Journal of Biological Chemistry, 154, 623-642. 